\title{
AVALIAÇÃO DOS RISCOS DE ACIDENTES EM ATIVIDADES DE PODA DE ÁRVORES NA ARBORIZAÇÃO URBANA DO DISTRITO FEDERAL ${ }^{1}$
}

\author{
Nilton César Fiedler ${ }^{2}$, Eduardo Hideki Sone ${ }^{2}$, Ailton Teixeira do Vale ${ }^{3}$, José de Fátima Juvêncio ${ }^{4}$ e \\ Luciano José Minette ${ }^{5}$
}

\begin{abstract}
RESUMO - Esta pesquisa teve por objetivo avaliar os riscos de acidentes em atividades de poda de árvores na arborização urbana do Distrito Federal. A coleta de dados foi feita com a aplicação de um questionário em forma de entrevista individual. Responderam ao questionário $94 \%$ dos funcionários, sendo $92 \%$ do total dos operadores de motosserra e $95 \%$ do total de auxiliares. Além disso, foi realizada uma avaliação qualitativa do risco de acidentes nas máquinas e equipamentos de poda e nos veículos de transporte dos trabalhadores, com a aplicação de um "checklist”. De acordo com os resultados, para a maioria dos operadores de motosserra $(78,3 \%)$, os equipamentos de proteção individual eram importantes e já os protegeram contra acidentes. Com relação ao índice de acidentes, 56,5\% dos operadores de motosserra afirmaram que sofreram algum tipo de acidente na empresa, e 65,2\% desses já presenciaram acidente no trabalho. Entre os auxiliares, 87,2\% responderam que o uso de equipamentos de proteção individual já evitou a ocorrência de acidentes no trabalho, 30,8\% disseram que sofreram acidente decorrente da atividade de poda e 48,7\% presenciaram acidentes no trabalho. Quanto aos equipamentos avaliados, todas as motosserras estavam em bom estado de conservação e possuíam sistema de segurança adequado. A maioria dos baús adaptados para o transporte dos trabalhadores sobre os caminhões apresentava má distribuição e insuficiência de janelas de ventilação. Os assentos tinham pouca inclinação para a coluna, e os cintos de segurança de duas pontas estavam mal fixados. Para um melhor desenvolvimento do trabalho, recomendam-se melhorar e facilitar o fornecimento dos equipamentos de proteção individual aos trabalhadores, oferecer cursos de aperfeiçoamento de técnicas de segurança no trabalho e treinamento aos recém-admitidos e melhorar o veículo de transporte dos trabalhadores, tanto no quesito segurança quanto no quesito conforto.
\end{abstract}

Palavras-chave: Ergonomia florestal, arborização urbana e riscos de acidentes.

\section{TREE PRUNING ACCIDENT RISK ASSESSMENT IN URBAN LANDSCAPING OF THE FEDERAL DISTRICT - BRAZIL}

\begin{abstract}
The objective of this study was to evaluate risks of accident in the tree pruning activity in the urban landscaping of the Brazilian Federal District. Data collection was carried out using a questionnaire that was answered through individual interviews. The questionnaire was answered by $94 \%$ of the workers, comprising $92 \%$ of the total chainsaw operators and $95 \%$ of the total helpers. Additionally, a qualitative accident risk assessment of machines, pruning equipment and transportation vehicles was carried out by means of a checklist. According to the results, for most chainsaw operators (78.3\%) the personal protective equipment was considered important and helped to keep them safe. In relation to accident index, $56.5 \%$ of chainsaw
\end{abstract}

\footnotetext{
${ }^{1}$ Recebido em $1^{\circ} .02 .2005$ e aceito para publicação em 10.11.2005.

${ }^{2}$ Departamentode Engenharia Rural da UniversidadeFederal doEspírito Santo, 29500-000Alegre-ES.E-mail:<fiedler@pesquisador.cnpq.br>.

${ }_{3}^{3}$ Departamento de Engenharia Florestal da Universidade de Brasília. Cx. P. 04357, 70910-900 Brasília-DF.

${ }^{4}$ Departamento de Educação Física da Universidade Federal de Viçosa, 36570-000 Viçosa-MG. E-mail: <josefati@ufv.br>.

${ }^{5}$ Departamento de Engenharia de Produção da Universidade Federal de Viçosa, 36570-000 Viçosa-MG. E-mail: <minette@ ufv.br>.
} 
operators affirmed that they had some type of accident in the company, and $65.2 \%$ said they had already witnessed accidents at work. Among helpers, $87.2 \%$ answered that the personal protective equipment had already saved them from accidents at work, $30.8 \%$ said they had accidents resulted from the pruning activity, and $48.7 \%$ witnessed accidents at work. As for the evaluated equipment, all chainsaws were in good conditions and with an adequate safety system. The majority of trunks adapted for worker transport on trucks showed insufficient number and defective distribution of ventilation windows. The inclination of seat back was inadequate and the 2-point safety belts were badly attached. For a better work development, it is recommended to improve and facilitate the supply of personal protective equipment to the workers, to provide training courses on safety techniques at work, training for newly-hired workers, and to improve both safety and comfort of worker transportation vehicles.

Keywords: Forest ergonomics, urban landscaping, risks of accidents.

\section{INTRODUÇÃO}

Uma das principais finalidades da arborização de vias públicas ou urbanas é satisfazer as necessidades mínimas do ser humano, trazendo para as cidades um pouco do ambiente natural (PEDROSA, 1983). A arborização urbana contribui enormemente para a qualidade de vida e o bem-estar da população; seja de um grande centro urbano ou de pequenas cidades. Assim, há melhoria do microclima, atenuação da poluição sonora, redução do impacto das chuvas e purificação do ar pela fixação de poeiras.

O Distrito Federal possui privilegiado programa de arborização urbana, que foi criado junto com a inauguração de Brasília. Desde então, já foram plantadas milhões de mudas de árvores pelas cidades, transformando a região num modelo urbanístico de arborização. No entanto, segundo Silva (2003), são necessárias manutenções constantes de poda das árvores, pois, inicialmente, muitas foram plantadas em locais não apropriados, como sob luminárias da iluminação pública, redes elétricas, cabos telefônicos ou muito próximos de residências e comércios.

Para Pedrosa (1983), o planejamento na implantação de novas áreas arborizadas é de extrema importância, pois se forem escolhidas espécies de porte compatível com o local, estas não necessitarão receber qualquer tipo de poda de manutenção.

Para o serviço de poda são utilizados diversos tipos de ferramentas e máquinas, que ajudam o ser humano na execução do trabalho. Entre as máquinas mais utilizadas estão as motopodas e as motosserras. Algumas dessas máquinas apresentam deficiências de projeto que podem levar a problemas de segurança e conforto para o operador.

R. Árvore, Viçosa-MG, v.30, n.2, p.223-233, 2006
A atividade de poda, como diversas atividades que envolvem o sistema ser humano - tarefa, exige muita atenção para que se possam evitar os acidentes, pois necessita, às vezes, de que o operador trabalhe sobre caminhões, escadas ou mesmo sobre as próprias árvores, manuseando as máquinas e, ou, equipamentos. Essas condições são extremamente favoráveis à ocorrência de acidentes, que podem ainda ser agravados caso o operador não esteja utilizando os equipamentos de proteção individual (EPIs) apropriados.

Segundo Alves Filho (2001), citando publicações da Organização Internacional do Trabalho (OIT), os trabalhadores dos diversos setores econômicos em todo o mundo sofrem, em média, 250 milhões de acidentes a cada ano. No ano de 1997 foram registrados cerca de 330 mil casos de acidentes fatais, sendo que, destes, aproximadamente 170 mil tinham como origem os trabalhos agrícola e florestal.

Para tanto, existem diversos fatores de agravamento dos riscos de acidentes, como ambiente de trabalho inadequado, elevada exigência de esforço físico, longas jornadas de trabalho, ineficiência no projeto de concepção das máquinas, ferramentas e equipamentos e o baixo nível de satisfação do trabalhador (SESI, 2002).

A avaliação dos riscos de acidentes é de suma importância para as atividades de poda, pois, segundo Fiedler (1998), seus resultados poderão ser empregados na prática com o intuito de melhorar e garantir a segurança e o bem-estar do trabalhador, aumentando, conseqüentemente, a eficiência do trabalho.

Esta pesquisa teve como objetivo geral a avaliação dos riscos de acidentes no trabalho na atividade de poda de árvores, na arborização urbana do Distrito Federal. 
Os objetivos específicos foram:

- Caracterizar os trabalhadores na atividade de poda quanto aos fatores humanos, condições e características do trabalho, saúde, acidentes no trabalho e nível de treinamento.

- Avaliar as características ergonômicas e de segurança das máquinas, ferramentas e dos equipamentos de poda utilizados pelos trabalhadores.

\section{MATERIAL E MÉTODOS}

\subsection{Região de estudos}

Esta pesquisa foi realizada com trabalhadores nas atividades de poda de árvores no plano-piloto de Brasília, Distrito Federal. O corte e a poda de árvores seguem uma política de intervenção mínima, baseada no Decreto $\mathrm{n}^{\circ} 14.783$, de 17 de junho de 1993, que dispõe sobre o tombamento de espécies arbóreas-arbustivas.

\subsection{População pesquisada}

A população pesquisada foi composta por operadores de poda e auxiliares, que atuavam em atividades de poda pelas áreas arborizadas de Brasília. Essa atividade era executada pelo método semimecanizado, com motosserras e motopodas. A empresa analisada contava na época do estudo com um total de 66 funcionários, sendo que 53 eram do quadro permanente e 13 , contratados temporariamente. As motosserras utilizadas pelas equipes eram da marca STIHL®, modelos 08, 051, 034, MS 360, 064 e 066. As motopodas avaliadas eram de duas marcas: STIHL®, modelos HT 70 e 75 e HOLEMAKER®, modelo Power Pruner PPT 2100.

Os equipamentos de poda analisados foram a corda, a escada e o carrinho de mão adaptado para carregar troncos. Os meios de transportes utilizados para o deslocamento para as frentes de trabalho eram caminhões, que possuíam cabines adaptadas à carroceria.

\subsection{Coleta dos dados}

A coleta dos dados de campo foi realizada entre os meses de setembro e dezembro de 2003, sendo dada em uma única fase. Para a caracterização dos trabalhadores, foi aplicado um questionário individual em forma de entrevista, em que foram levantados os dados pessoais, saúde, caracterização da atividade de poda, segurança, treinamento e nível de satisfação.
Os dados foram coletados através de um censo da população de operadores e auxiliares que estavam em atividade.

\subsubsection{Caracterização do trabalhador nas atividades depoda}

A caracterização do trabalhador em atividades de poda foi realizada com a aplicação de um questionário em forma de entrevista individual. Todos os trabalhadores avaliados responderam às mesmas perguntas, individualmente, no local do trabalho.O questionário continha perguntas relativas aos fatores humanos no trabalho, condições de trabalho, condições de saúde, segurança no trabalho, treinamento e reciclagem e nível de satisfação dos trabalhadores.

Os fatores humanos foram avaliados pelos dados pessoais dos trabalhadores referentes à idade, estado civil, número de filhos, peso e estatura, escolaridade, posse de bens e vícios.

Nas condições de trabalho foram avaliadas as características físicas do trabalho, o motivo pelo qual exercia a atividade, jornada diária, atividades extras, adicionais de produtividade, ciclo de trabalho, as preferências, o relacionamento com a chefia e com os colegas, os pontos que mais afetavam o desempenho no trabalho e os fatores externos que interferiam no trabalho.

A condição de saúde dos trabalhadores foi avaliada com base no histórico da saúde e situação atual, doenças adquiridas no trabalho, freqüência de afastamentos por problemas de saúde e seus motivos, problemas relacionados a sono, nível de cansaço após ou durante o trabalho e exames médicos periódicos.

A respeito das condições de segurança no trabalho, foram abordados na entrevista o uso, a reposição, o fornecimento, a obrigatoriedade do uso e os incômodos causados pelos EPIs. Além disso, foi avaliada a freqüência de acidentes, a situação de maior risco no trabalho e o nível de segurança dos equipamentos, máquinas e ferramentas de trabalho.

Relativo ao treinamento e reciclagem, os trabalhadores foram questionados sobre o treinamento recebido ao serem contratados, tipo e duração do período de treinamento, tempo necessário para adaptação ao trabalho, cursos periódicos oferecidos pela empresa, necessidade de reciclagem e rodízios de atividades entre os funcionários.

R. Árvore, Viçosa-MG, v.30, n.2, p.223-233, 2006 
Para a avaliação do nível de satisfação, os trabalhadores responderam a uma lista de 14 questões referentes a: satisfação no trabalho, relacionamento com os colegas, grau de interesse pelo serviço e motivação. Cada questão foi avaliada separadamente pelo trabalhador, em que ele atribuía uma pontuação de acordo com o Quadro 1. A pontuação para obter a máxima e mínima satisfações seria de 70 e 14 pontos, respectivamente. A escala de satisfação no trabalho foi adaptada de Brayfield e Rothe por Sant' anna (1992).

\subsubsection{Avaliação qualitativa do risco de acidentes nas máquinas e equipamentos}

A avaliação do risco de acidentes nas máquinas e equipamentos foi realizada de forma qualitativa por meio de observações e medições anotadas em uma planilha desenvolvida para essa finalidade ("check-list").

Os itens avaliados foram o sistema de segurança, estado de conservação e manutenção. Foram observados o material de confecção, adaptação, conforto e segurança no trabalho dos equipamentos.

Os EPIs (botas, luvas, capacete, protetor auricular, calça especial, óculos e cinto de segurança) foram avaliados quanto ao estado de conservação e ao modo de uso pelos trabalhadores. Quanto ao cinto de segurança, foi observada ainda a sua fixação ao corpo do operador e à árvore.

No meio de transporte foram avaliados os sistemas de ventilação, cintos de segurança e as escadas de acesso.

\subsection{Descrição das atividades do ciclo de trabalho}

As atividades que faziam parte do ciclo de trabalho do operador de motosserra nas atividades de poda de árvores eram: manutenção da máquina (motosserra ou motopoda), preparar a escalada na árvore (apoiar a escada e amarrar o cinto de segurança à árvore), corte de galhos em cima da árvore ou no chão, corte da árvore e ajuda aos auxiliares.

Quadro 1 - Escores atribuídos a cada pontuação da escala de satisfação

Table 1 - Score assigned to each punctuation in the satisfaction scale

\begin{tabular}{cc}
\hline Pontuação & Escore \\
\hline 1 & Discordo muito \\
2 & Discordo \\
3 & Indeciso \\
4 & Concordo \\
5 & Concordo muito \\
\hline
\end{tabular}

Fonte: Brayfield e Rothe, adaptado por Sant'anna (1992).

R. Árvore, Viçosa-MG, v.30, n.2, p.223-233, 2006
As atividades que faziam parte do ciclo do trabalho dos auxiliares eram: auxiliar o operador, arrastar galhos, carregar troncos, carregar e descarregar caminhões e limpeza da área. Entre os auxiliares não havia rodízio de atividades; segundo eles, por não existir uma ordem seqüencial das atividades.

\section{RESULTADOS E DISCUSSÃO}

\subsection{Caracterização do trabalhador nas atividades de poda}

\subsubsection{Caracterização dos fatores humanos no trabalho}

No Quadro 2, mostra-se a caracterização dos fatores humanos em atividades de poda de árvores no Distrito Federal.

A média do tempo na função encontrada foi de 10,4 anos para os operadores. No entanto, os elevados valores de desvio-padrão $(6,4)$ e amplitude (20 anos) indicaram a existência de operadores de vários níveis de experiência. A média de idade foi de 41 anos, altura média de $169 \mathrm{~cm}$ e 73,1 kg de peso. O tempo médio na função foi bem superior ao encontrado por Fiedler (1998) (2,4 anos) nos trabalhadores das empresas prestadoras de serviço em colheita de madeira no norte do Estado da Bahia.

Entre os auxiliares, a idade média foi de 40,4 anos, e o tempo médio na função, de 8,7 anos, com alto desviopadrão $(5,8)$ e amplitude $(21,5$ anos $)$. As médias de altura e peso foram de $169 \mathrm{~cm}$ e $72,6 \mathrm{~kg}$.

O porcentual de operadores casados $(60,9 \%)$ foi aproximadamente três vezes maior que o de amasiados $(21,7 \%)$ e solteiros $(17,4 \%)$. Cada operador tinha em média 2,9 filhos.

O número de casados $(48,7 \%)$ entre os auxiliares foi maior que o número de solteiros $(28,2 \%)$ e amasiados $(23,1 \%)$. A média de filhos por trabalhador foi de 2,2, um pouco menor que a média obtida entre os operadores.

O nível de escolaridade apresentou-se com graus de escolaridade bastante divididos e com apenas um operador de motosserra analfabeto $(4,4 \%)$. O porcentual de analfabetos foi bem inferior ao encontrado para trabalhadores florestais por Sant' anna (1992) (24,0\%) e por Fiedler (1998) (29,1\%). Os maiores porcentuais foram encontrados entre os operadores que cursaram o primário e o $1^{\circ}$ grau completo, com $26,1 \%$ cada um. Em seguida ficaram $1^{\circ}$ grau incompleto $(17,4 \%), 2^{\circ}$ grau completo $(13,04 \%)$ e $2^{\circ}$ grau incompleto $(8,7 \%)$. 
Quadro 2 - Fatores humanos dos trabalhadores nas atividades de poda de árvores Table 2 - Human factor in tree pruning safety

\begin{tabular}{|c|c|c|c|c|c|c|c|c|}
\hline \multirow{2}{*}{$\begin{array}{c}\text { Característica } \\
\text { avaliada }\end{array}$} & \multicolumn{4}{|c|}{ Operadores } & \multicolumn{4}{|c|}{ Auxiliares } \\
\hline & Mínimo & Máximo & Média & D.P. & Mínimo & Máximo & Média & D.P. \\
\hline $\begin{array}{l}\text { Tempo na função } \\
\text { (anos) }\end{array}$ & 2 & 22 & 10,4 & 6,4 & 0,5 & 22 & 8,7 & 5,8 \\
\hline Idade (anos) & 26 & 66 & 41 & 9,8 & 26 & 66 & 40,4 & 8,9 \\
\hline Peso (Kg) & 58 & 97 & 73,1 & 11,2 & 53 & 92 & 72,6 & 10,3 \\
\hline Altura $(\mathrm{cm})$ & 157 & 188 & 169 & 6,8 & 138 & 187 & 169 & 8,2 \\
\hline Casados (\%) & - & - & 60,9 & - & - & - & 48,7 & - \\
\hline $\begin{array}{l}\text { No de filhos por } \\
\text { trabalhador }\end{array}$ & $\mathrm{o}$ & 12 & 2,9 & 2,5 & $\mathrm{o}$ & 7 & 2,2 & 1,7 \\
\hline Escolaridade (\%) & $4,4(a)$ & $26,1(p c)$ & - & 2,1 & $2,6(\mathrm{si})$ & $28,2(p i)$ & - & 4 \\
\hline Origem rural $(\%)$ & - & - & 73,9 & - & - & - & 53,8 & - \\
\hline $\begin{array}{l}\text { Possui casa } \\
\text { Própria }(\%)\end{array}$ & - & - & 73,9 & - & - & - & 64,1 & - \\
\hline Possui vícios (\%) & - & - & 60,9 & - & - & - & 51,3 & - \\
\hline
\end{tabular}

D.P. $=$ desvio-padrão; $\mathrm{a}=$ analfabetos $; \mathrm{pc}=1^{\circ}$ grau completo; $\mathrm{pi}=1^{\circ}$ grau incompleto; $\mathrm{e}$ si $=2^{\circ}$ grau incompleto.

A taxa de analfabetos entre os auxiliares foi de $10,3 \%$ (quatro trabalhadores), um pouco mais que o dobro encontrado entre os operadores. A maior taxa de escolaridade foi obtida entre os auxiliares, com $1^{\circ}$ grau incompleto $(28,2 \%)$, seguido do $2^{\circ}$ grau completo $(25,6 \%)$, primário $(23,1 \%), 1^{\circ}$ grau completo $(10,3 \%)$ e $2^{\circ}$ grau incompleto $(2,6 \%)$.

A maioria dos operadores $(73,9 \%)$ era de origem rural, o mesmo porcentual dos que possuíam casa própria. Só os auxiliares tiveram porcentuais bastante equilibrados entre a origem rural $(53,8 \%)$ e a urbana $(46,2 \%)$. Quanto à casa própria, $64,1 \%$ possuíam. A origem rural dos trabalhadores também foi superior nos trabalhos realizados por Sant'anna e Malinovski (2002), com operadores de motosserra em Minas Gerais, Minette (1996) com operadores de motosserra no interior de São Paulo e Fiedler (1998) no norte da Bahia, com valores médios de 75,9\%,75,7\% e 68,9\%, respectivamente.

Com relação aos vícios, o porcentual de operadores que consumiam bebida alcoólica foi alto $(34,8 \%)$, como também de fumantes $(43,5 \%)$. Esses índices não são desejáveis, uma vez que o vício em cigarro e bebida pode acarretar problemas de saúde, além de reduzir o nível de atenção no trabalho. Para os auxiliares, o porcentual de fumantes e consumidores de bebida alcoólica foi o mesmo $(33,4 \%)$, com taxa um pouco menor que a encontrada entre os operadores, mas não menos preocupante. Os trabalhadores, tanto operadores quanto auxiliares, responderam que consumiam bebida alcoólica, principalmente nos finais de semana. De acordo com
Souza e Minette (2002), esses vícios podem comprometer seriamente os níveis de saúde do trabalhador, acarretando, com o tempo, elevado nível de absenteísmo.

\subsubsection{Condições de trabalho}

Os dados referentes às condições e características gerais do trabalho de poda de árvores são apresentados no Quadro 3.

A jornada de trabalho era de oito horas diárias (das 8 às 17 horas) para todos os trabalhadores. A frequiência de trabalhadores que executavam horas extras era muito alta $(69,6 \%$ dos operadores e $69,2 \%$ dos auxiliares), variando entre 24 e 32 horas extras por mês, sempre nos finais de semana. Todos salientaram que recebiam adicional pelas horas extras.

Quadro 3 - Condições e características do trabalho Table 3 - Conditions and characteristics of tree pruning work

\begin{tabular}{|c|c|c|}
\hline \multirow{2}{*}{ Caracteristica avaliada } & \multicolumn{2}{|c|}{ Freqüência relativa (\%) } \\
\hline & Operadores & Auxiliares \\
\hline Trabalho considerado medianamente pesado & 65,2 & 69,2 \\
\hline Executam horas extras & 69,6 & 69,2 \\
\hline Possui outra fonte de renda & 34,8 & 28,2 \\
\hline Gosta do trabaho & 56,5 & 43,6 \\
\hline Executam rodizio nas fases do ciclo & 87 & 0 \\
\hline Atvidade mais cansativa & 47,8 (escalar a árvore) & 41,0 (carregar tronco) \\
\hline Fator que mais interfere no trabalho & 21,7 (insegurança) & $\begin{array}{r}30,7 \text { (falta de } \\
\text { orientação) }\end{array}$ \\
\hline Fator externo que mais interfere no trabalho & 65,2 (temperatura) & $\begin{array}{r}48,7 \text { (temperatura } \mathrm{e} \\
\quad \text { rúdo elevados) }\end{array}$ \\
\hline Vontade de mudar de atividade & 39,1 & 53,9 \\
\hline
\end{tabular}

R. Árvore, Viçosa-MG, v.30, n.2, p.223-233, 2006 
Quanto à existência de outras fontes de renda, $34,8 \%$ dos operadores responderam que possuíam. As atividades mais citadas foram trabalho de pedreiro, serviço de poda, serralheria e fretes.

Apenas 28,2\% dos auxiliares responderam que possuíam outra fonte de renda. As atividades mais citadas foram a de jardinagem $(27,3 \%)$ e a de pedreiro $(18,2 \%)$. Foram citados também as atividades de garagista, músico, segurança, caixa e o próprio serviço de poda.

Para 65,2\% dos operadores, o trabalho foi considerado medianamente pesado. A maioria dos trabalhadores $(56,5 \%)$ está no trabalho porque gosta do serviço de poda, outros $30,4 \%$ estão por necessidade e por não terem outra opção de emprego. Para a maioria dos auxiliares $(69,2 \%)$, a atividade foi considerada medianamente pesada, e outros $23,1 \%$ classificaramna como pesada. $O$ índice dos auxiliares que gostam do trabalho $(43,6 \%)$ foi um pouco menor que o porcentual obtido entre os operadores. Outros 25,6\% afirmaram que estavam nesse trabalho pela necessidade e falta de outra opção de emprego. Constatou-se também que $15,4 \%$ dos auxiliares já haviam trabalhado em outras seções dentro da empresa e estavam nessa função por solicitação da própria empresa.

A atividade mais cansativa apontada pelos operadores de motosserra foi a escalada da árvore $(47,8 \%)$ e em segundo lugar, ocorte (derrubada) daárvore (21,7\%). Para os auxiliares, a atividade considerada mais cansativa citada foi o manuseio dos troncos (41\%). Outros $17,9 \%$ dos entrevistados responderam que o carregamento e descarregamento do caminhão eram mais cansativos.

Segundo $21,7 \%$ dos operadores, o principal responsável pela queda do desempenho na atividade era a insegurança, outros $17,4 \%$ consideraram a baixa remuneração e falta de habilidade e $13,1 \%$ priorizaram a falta de orientação dos encarregados. Para os auxiliares, a queda do desempenho no trabalho ocorria principalmente pela falta de orientação dos encarregados $(30,8 \%)$, baixa remuneração $(32,1 \%)$, elevada pressão para a produção $(15,4 \%)$ e insegurança $(9,7 \%)$.

Entre os fatores externos que afetavam o desempenho, $65,2 \%$ dos operadores responderam que a temperatura elevada incomodava mais durante o trabalho, seguidos da radiação solar $(52,2 \%)$ e fuligem $(39,1 \%)$. A maioria dos auxiliares respondeu que o ruído e a temperatura elevados $(48,7 \%)$ eram os fatores externos de maior incômodo. Outros $41 \%$ responderam ser a radiação solar, $35,9 \%$ a fuligem, $10,3 \%$ o vento e $7,7 \%$ a iluminação e vibração elevadas.

A maioria dos operadores respondeu que não queriam mudar de atividade, no entanto $39,1 \%$ manifestaram interesse em mudar. Desses que querem mudar de atividade, $66,7 \%$ sentiam necessidade de aumentar a renda familiar. Em seu trabalho, Minette (1996) encontrou um alto porcentual de operadores $(56,7 \%)$ que tinha vontade de mudar de atividade por esse mesmo motivo.

Entre os auxiliares, a maioria $(53,9 \%)$ tinha interesse em mudar de atividade. Dos interessados, 76,2\% afirmaram que necessitavam aumentar a renda familiar e 7,7\% queriam sair por causa da baixa remuneração.

\subsubsection{Condições de saúde}

A maioria dos operadores entrevistados $(95,7 \%)$ não tinha problemas de saúde antes dessa atividade, como também não adquiriram problemas de saúde no trabalho atual (87\%). Já em relação aos afastamentos temporários por problema de saúde, 17 operadores $(73,9 \%)$ responderam que tiraram licença. Desse total, 11 afastamentos $(64,7 \%)$ foram por acidente de trabalho. Entre os auxiliares, $79,5 \%$ responderam que não tiveram problemas de saúde antes de assumirem a atual função. A grande maioria dos trabalhadores $(87,2 \%)$ também não adquiriu nenhum problema originário do trabalho atual. Um pouco mais da metade dos servidores (59\%) afirmou que ficaram afastados por motivo de saúde, no entanto apenas $21,7 \%$ dos afastamentos foram por acidente de trabalho.

Em relação aos problemas de sono, a maioria dos operadores $(87 \%)$ e auxiliares $(89,7 \%)$ respondeu que não possuíam problemas e dormiam em média oito horas por dia.

Um pouco mais da metade dos operadores $(56,5 \%)$ afirmou que sentiam dores no corpo durante ou após o trabalho. As regiões mais afetadas eram a coluna $(47,8 \%)$ e o braço $(21,7 \%)$. O excesso de cansaço após a jornada de trabalho era comum para $73,9 \%$ dos trabalhadores. Em seu trabalho, Minette (1996) constatou que $64,8 \%$ dos operadores apresentavam algum sintoma de lombalgia. Segundo esse autor, a lombalgia constitui um dos principais problemas de saúde dos operadores de motosserra da atualidade. 
Entre os auxiliares, $61,5 \%$ relataram dores no corpo durante ou após a jornada de trabalho. Igualmente aos operadores, a maioria $(79,2 \%)$ dos auxiliares reclamou de dores na coluna. Outros $16,7 \%$ reclamaram de dores nas pernas e no tórax e $8,3 \%$, nos braços. E 74,4\% responderam que sentiam muito cansaço no final da jornada de trabalho. Fiedler (1998) constatou em seu trabalho que tanto operadores quanto auxiliares estavam sendo severamente prejudicados com a adoção de posturas incorretas no trabalho, o que pode causar problemas graves nas costas e pernas dos trabalhadores.

Quanto aos exames médicos periódicos, 73,9\% dos operadores responderam que faziam. Os exames mais realizados foram de audiometria $(100 \%)$, sangue $(70,6 \%)$, urina $(47,1 \%)$ e fezes $(41,2 \%)$. Entre os auxiliares entrevistados, $66,7 \%$ afirmaram que faziam exames periódicos. Os exames mais realizados eram: audiometria $(57,7 \%)$, sangue $(92,3 \%)$ e urina e fezes $(61,5 \%)$. Constatouse uma não-uniformidade nas respostas dos trabalhadores, pois tanto os funcionários antigos quanto os novos afirmaram que faziam um ou outro exame. Segundo o Posto Médico da Empresa, nos últimos anos foram realizados exames médicos periódicos de audiometria, sangue, urina e fezes, este último apenas para os auxiliares.

\subsubsection{Segurança no trabalho}

No Quadro 4, mostra-se o resultado da entrevista quanto aos itens de segurança no trabalho. A maioria dos operadores de motosserra e auxiliares utiliza os EPIs necessários à segurança no trabalho de poda (capacete, botas, luvas, protetor auricular, cinto de segurança e calça especial com camadas de náilon).
A Figura 1 ilustra a freqüência relativa dos trabalhadores que estavam utilizando os EPIs no momento da entrevista.

O cinto de segurança e a calça especial eram distribuídos apenas para os operadores em função da necessidade de uso específico na operação. Para 78,3\% dos operadores, os EPIs são importantes e acreditam ter sido salvos por eles. Entre os auxiliares, o índice sobe para $87,2 \%$. Isso demonstra a importância dada pelos trabalhadores sobre o uso dos EPIs e a necessidade de manter a reposição integral e de boa qualidade desses equipamentos. Segundo Sant'anna e Malinovski (2002), todos os operadores de motosserra entrevistados em seu trabalho consideraram necessária à utilização dos EPIs, e a maioria $(58,6 \%)$ afirmou que deixou de sofrer acidente de trabalho por estar usando tais equipamentos.

Apesar de a empresa fornecer o cinto de segurança tipo alpinista, o cinto de segurança utilizado por todos os operadores era do tipo mosquetão. Todos reclamaram do desconforto causado pelo cinto de segurança tipo alpinista para a execução do trabalho. Segundo eles, o cinto tipo mosquetão é mais prático para o trabalho e confortável. Outro equipamento que os operadores relataram ser desconfortável foi o capacete $(26,1 \%)$, principalmente por esquentar muito e cair constantemente da cabeça. Dos operadores que usavam óculos de proteção $(52,2 \%), 33,3 \%$ reclamaram que as lentes embaçavam muito devido à transpiração. Segundo Saliba (1997), as empresas devem ter uma preocupação especial com o grau de periculosidade e insalubridade do trabalho, oferecendo sempre aos trabalhadores condições seguras e saudáveis no ambiente de trabalho.

Quadro 4 - Resultado das perguntas referentes à segurança no trabalho Table 4-Answers of questions referring to safety at work

\begin{tabular}{|c|c|c|}
\hline \multirow{2}{*}{ Característica avaliada } & \multicolumn{2}{|c|}{ Freqüência relativa (\%) } \\
\hline & Operadores & Auxiliares \\
\hline Desconforto dos EPI's & 60,9 & 28,2 \\
\hline Reposição dos EPI's & 78,3 (insatisfatório) & 61,5 (insatisfatório) \\
\hline Reposição integral dos EPI's & 69,6 (satisfatório) & 59 (satisfatório) \\
\hline $\begin{array}{c}\text { Trabalhadores que sofreram } \\
\text { acidentes no trabalho }\end{array}$ & 56,5 & 30,7 \\
\hline Salvos pelos EPI's & 78,3 & 87,2 \\
\hline $\begin{array}{c}\text { Presenciaram acidente no } \\
\text { trabalho }\end{array}$ & 65,2 & 48,7 \\
\hline Operação mais perigosa & $\begin{array}{c}34,8 \text { (podar em cima da } \\
\text { árvore) }\end{array}$ & 23,7 (próximo a rodovias) \\
\hline Maior motivo dos acidentes & 82,6 (falta de atenção) & 66,7 (falta de atenção) \\
\hline Sugestões para segurança & $\begin{array}{c}52,2 \text { (aumentar a } \\
\text { atenção) }\end{array}$ & $\begin{array}{c}53,8 \text { (aumentar a } \\
\text { atenção) }\end{array}$ \\
\hline
\end{tabular}

R. Árvore, Viçosa-MG, v.30, n.2, p.223-233, 2006 


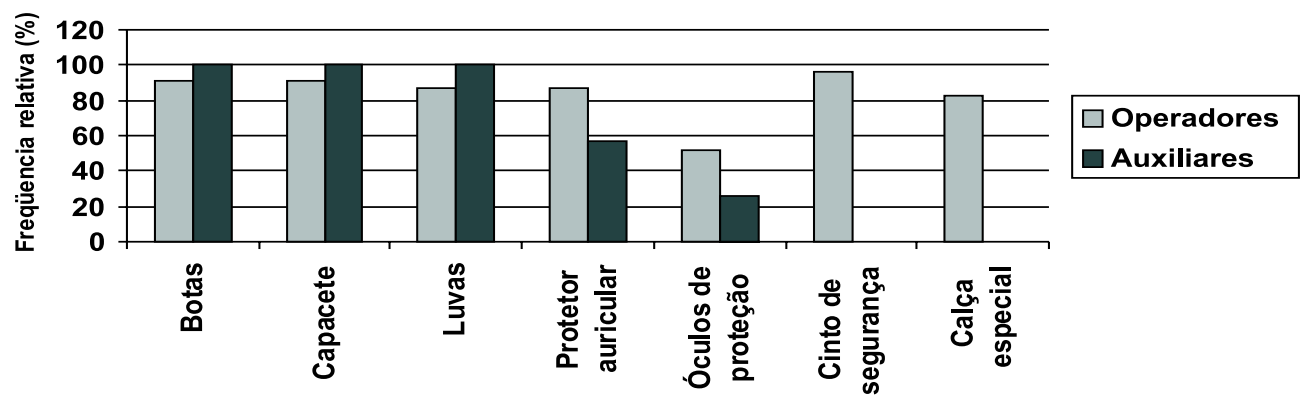

Figura 1 - Equipamentos de proteção individual em uso no momento das entrevistas. Figure 1 - Protective equipment used during interview.

Dos auxiliares que reclamaram de incômodos causados pelos EPIs $(28,2 \%)$, o protetor auricular acoplado ao capacete foi a maior queixa $(63,6 \%)$. Eles relataram que esses dois equipamentos em conjunto dificultavam o manuseio de cargas no ombro e aumentavam a sensação de peso do capacete.

Para a maioria dos operadores $(69,6 \%)$ e auxiliares (59\%), a Empresa fornece integralmente os EPIs, no entanto a forma da reposição não foi considerada satisfatória (78,3\% dos operadores e $61,5 \%$ dos auxiliares). Dentre os operadores insatisfeitos, $50 \%$ reclamaram da falta constante dos EPIs no depósito de distribuição, $38,9 \%$ reclamaram da má qualidade dos EPIs adquiridos e do excesso de burocracia para a reposição. Mais da metade dos auxiliares $(58,3 \%)$ reclamou da falta de EPIs no depósito de distribuição, 37,5\% disseram que o maior empecilho é a burocracia e $12,5 \%$ queixaramse da má qualidade dos EPIs adquiridos.

Quanto aos acidentes de trabalho, mais da metade dos operadores $(56,5 \%)$ afirmou ter sofrido acidente decorrente da atividade de poda na empresa, valor bem superior ao encontrado por Sant' anna e Malinovski (2002) em operação de corte florestal com motosserra $(44,8 \%)$. A parte do corpo mais atingida foi a perna $(53,8 \%)$, seguida da cabeça e mãos (23\%). Para 46,2\% desses operadores, a principal razão foi o próprio descuido, e 28,2\% dos auxiliares sofreram acidente em atividade de poda. As partes do corpo mais atingidas foram a cabeça e os pés (25\%). Segundo eles, o motivo que mais causou tais acidentes foi o próprio descuido $(50 \%)$.

A maioria dos operadores $(65,2 \%)$ respondeu que já presenciou algum acidente no trabalho, e o acidente de maior ocorrência foi a queda de operador da árvore durante a escalada para a poda $(53,3 \%)$. Entre os auxiliares que presenciou algum acidente no trabalho $(48,7 \%)$, a maioria $(26,3 \%)$ viu o operador cair da árvore. Outros auxiliares presenciaram o colega se cortar com motosserra $(21,1 \%)$ e a queda de galho sobre o trabalhador $(15,8 \%)$.

A atividade mais perigosa apontada pelos operadores foi o corte com motosserra escalando árvores (43,5\%). Como cada árvore a ser escalada é uma situação diferente, e muitas vezes inusitada, o uso da motosserra se torna uma atividade perigosa, pois em muitas situações o operador não tem como se prender ou apoiar com segurança à árvore. Já para $26,1 \%$ a operação mais perigosa é a execução do trabalho próximo de redes elétricas.

A opinião dos auxiliares sobre as atividades mais perigosas foi dividida entre a execução do trabalho próximo a estradas e rodovias $(23,1 \%)$, a derrubada de árvores $(20,5 \%)$ e auxílio ao operador $(17,9 \%)$, que inclui puxar corda para direcionar a queda de galhos e árvores, segurar escadas durante a subida do operador à árvore e reabastecer a motosserra.

Quando questionados sobre as causas possíveis dos acidentes no trabalho, a grande maioria $(82,6 \%)$ respondeu que a falta de atenção foi o principal motivo. Foram mencionadas também a falta do uso de EPIs (26,1\%), a displicência e a má qualidade dos equipamentos de poda $(21,7 \%)$, a má qualidade dos EPIs, falta de treinamento $(8,7 \%)$ e pressão para produção $(4,4 \%)$. Para $35 \%$ dos operadores entrevistados por Sant'anna e Malinovski (2002), a falta de atenção também foi considerado o maior motivo causador de acidentes. Segundo Sant'anna (1992), os principais motivos para a falta de atenção dos operadores são o sono e a fadiga. 
A resposta dos auxiliares seguiu a mesma linha dos operadores relatando a falta de atenção do trabalhador como a maior responsável pelos acidentes $(66,7 \%)$, seguida da falta de uso dos EPIs $(25,6 \%)$. Também foram citadas a falta de orientação $(10,3 \%)$ e a displicência $(7,7 \%)$.

Pra diminuir os riscos de acidentes e aumentar a segurança no trabalho, a principal sugestão foi aumentar a atenção $(52,2 \%)$. Foram sugeridos também o fornecimento de equipamentos de poda de melhor qualidade e em maior quantidade, principalmente as cordas e escadas $(43,5 \%)$, usar sempre os EPIs $(26,1 \%)$; melhorar o salário $(17,4 \%)$; oferecer mais treinamentos (13\%); melhorar a orientação $(8,7 \%)$; e melhorar o transporte para o deslocamento $(4,4 \%)$.

A recomendação para a diminuição dos riscos de acidentes da maioria dos auxiliares foi aumentar o próprio nível de atenção $(53,8 \%)$, treinamento adequado $(25,6 \%)$, uso obrigatório dos EPIs $(23,1 \%)$, melhor fornecimento dos EPIs (20,5\%) e melhor qualidade dos equipamentos de poda $(17,9 \%)$.

\subsubsection{Treinamento e reciclagem}

Apenas $8 \%$ dos operadores de motosserra responderam que tiveram treinamento ao assumir a função de operador de motosserra na empresa. O tempo médio foi de cinco dias, e nenhum deles considerou o treinamento suficiente, necessitando de mais aulas práticas. Todos os treinados salientaram que gostariam de fazer cursos de aperfeiçoamento de nó e amarração, técnicas de salvamento, manutenção das motosserras e motopodas e rapel. O tempo médio necessário para a adaptação à função foi de oito meses. Apenas 11,3\% dos auxiliares afirmaram que tiveram treinamento de uma semana ao assumir a função, sendo que $57,1 \%$ desse total o considerou suficiente. Do total de auxiliares, apenas $28,5 \%$ salientaram que gostariam de fazer cursos de aperfeiçoamento de rapel, operação com motosserra, nó e amarração. Para os auxiliares, foi necessário em média um mês para a adaptação.

\subsubsection{Nível de satisfação dos trabalhadores}

O nível de satisfação dos trabalhadores na atividade de poda está expresso na Figura 2. A pontuação máxima obtida foi de 70 e, a mínima, de 41 pontos entre os operadores e máximo de 67 e mínimo de 30 entre os auxiliares.

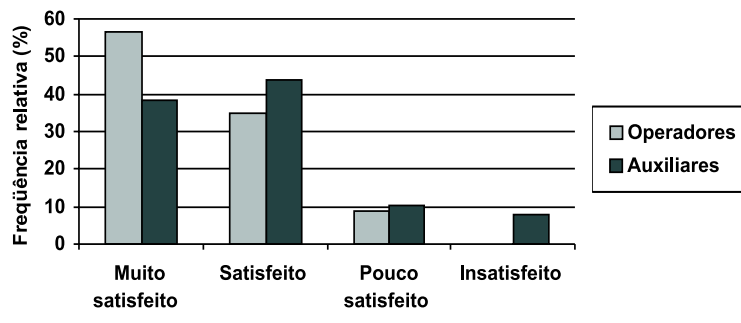

Figura 2 - Nível médio de satisfação dos trabalhadores da atividade de poda.

Figure 2-Average level of satisfaction of workers in pruning activity.

A grande maioria dos operadores estava muito satisfeita $(56,5 \%)$ ou satisfeita $(34,8 \%)$ com o seu trabalho. Outros $8,7 \%$ mostraram-se pouco satisfeitos, e nenhum operador atingiu a escala de insatisfeito ou muito insatisfeito. Entre os auxiliares, a maioria também estava muito satisfeita $(38,5 \%)$ e satisfeita $(43,6 \%), 10,3 \%$ estavam pouco satisfeitos e $7,7 \%$, insatisfeitos. Esses resultados mostraram-se muito bons, uma vez que o trabalhador satisfeito na função tende a desenvolver melhor o trabalho e com mais segurança e atenção.

\subsection{Avaliação qualitativa do risco de acidentes nas máquinas e equipamentos}

Todas as oito equipes de poda tiveram suas máquinas, equipamentos e ferramentas avaliados individualmente por cada item do "check-list" (Figura 3).

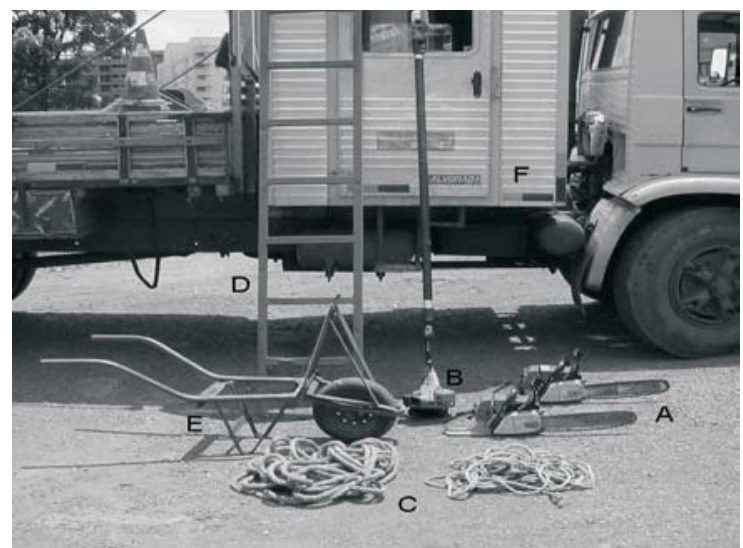

A) motosserra; B) motopoda; C) cordas; D) escada; E) carrinho adaptado para carregar troncos; e F) cabine adaptada no veículo de transporte dos trabalhadores.

Figura 3 - Itens avaliados qualitativamente no "check-list". Figure 3 -Qualitative items evaluated by the checklist.

R. Árvore, Viçosa-MG, v.30, n.2, p.223-233, 2006 
Os resultados da avaliação qualitativa das máquinas, ferramentas e equipamentos utilizados na atividade de poda são apresentados no Quadro 5.

As equipes possuíam em média três motosserras dotadas de sistema de segurança em boas condições de funcionamento. Apresentavam-se bem conservadas, e sua manutenção era de boa qualidade e feita regularmente.

Apesar de as motopodas avaliadas terem sido bem classificadas, apenas metade das equipes utilizava a máquina. Das equipes sem a máquina, três não possuíam e a outra estava com a motopoda quebrada. Quando uma dessas equipes necessitava de motopoda para a execução de uma atividade, era necessário utilizar a de outra equipe. O desejável seria que todas as equipes possuíssem sua própria máquina, aumentando a agilidade no trabalho.

Os equipamentos e ferramentas de poda avaliados foram as cordas, escada e o carrinho adaptado para carregar troncos. As cordas utilizadas pelos trabalhadores eram de sisal, e cada equipe possuía cordas de vários diâmetros e comprimentos adequados. Elas não apresentaram problemas quanto ao deslizamento. As escadas eram confeccionadas de madeira, ferro ou fibra de vidro e, como não eram padronizadas, cada equipe tinha algum tipo de dificuldade ou problema na sua utilização. As maiores reclamações foram quanto ao peso, principalmente a de madeira; algumas escadas eram muito curtas e outras, de pouca estabilidade. Quanto ao carrinho adaptado para carregar toras e troncos, uma das equipes não o possuía e em outra equipe esse tinha sido improvisado pelos próprios trabalhadores. No geral estavam em bom estado de conservação e não apresentavam sérios desconfortos.

Quadro 5 - Avaliação qualitativa das máquinas, ferramentas e equipamentos

Table 5 -Qualitative evaluation of machines, tool and equipment

\begin{tabular}{lc}
\hline Característica avaliada & Avaliação \\
\hline Motosserra & Muito bom \\
Motopoda & Bom \\
Cordas & Bom \\
Escadas & Ruim \\
Carrinhos & Regular \\
EPIs & Bom \\
Transporte para deslocamento & Ruim \\
\hline
\end{tabular}

R. Árvore, Viçosa-MG, v.30, n.2, p.223-233, 2006
Os EPIs estavam em bom estado de conservação. Apenas as luvas apresentavam-se um pouco gastas. A maioria utilizava os EPIs de forma correta. Quanto ao cinto de segurança, constatou-se que esse EPI não tinha boa fixação à árvore e a corda de ficção era de náilon, que aparentemente não era de boa qualidade, oferecendo risco de acidente aos operadores.

Apesar de todos os meses as equipes fazerem rodízio dos caminhões, o transporte de deslocamento para as frentes de trabalho foi o que obteve classificação considerada ruim. A maioria das cabines de transporte não possuía boa ventilação, pois existiam apenas janelas laterais. Os cintos de segurança foram classificados como muito ruins, pois muitos estavam quebrados e em péssimo estado de conservação.

Notou-se também que a maioria dos trabalhadores não usava os cintos por incômodos causados. $\mathrm{O}$ encosto do assento não possuía boa inclinação, causando mais incômodos aos trabalhadores. A escada de acesso à cabine possuía o primeiro degrau muito alto, dificultando tanto a subida quanto a descida do trabalhador.

\section{CONCLUSÕES}

- Os trabalhadores na atividade de poda de árvores na arborização urbana do Distrito Federal tinham alto tempo na atividade, e idades médias superiores a 40 anos; eram casados $(60,9 \%)$, possuidores de casa própria $(73,9 \%)$, de origem rural, com baixo índice de analfabetismo $(4,4 \%)$ e com alto porcentual de consumidores de cigarros e ingestão de bebidas alcoólicas.

- A jornada de trabalho era de oito horas diárias, mais horas extras preferencialmente nos finais de semana. Para a maioria dos operadores $(65,2 \%)$ e auxiliares $(56,5 \%)$, o trabalho era medianamente pesado e tinha gosto pelo trabalho. O rodízio das atividades do ciclo de trabalho era feito apenas entre os operadores. A atividade mais cansativa para os operadores era a escalada de árvore $(47,8 \%)$ e para os auxiliares, carregar troncos $(41 \%)$. Para os operadores, o desempenho no trabalho era afetado principalmente pela insegurança $(21,7 \%)$ e para os auxiliares, pela falta de orientação $(30,8 \%)$. A temperatura e o ruído elevados eram os fatores externos que mais atrapalhavam o desempenho. A maioria dos operadores $(56,5 \%)$ não queriam mudar de atividade, e um pouco mais da metade dos auxiliares desejava mudar $(53,9 \%)$. 
- A grande maioria dos operadores $(95,7 \%)$ e auxiliares $(79,5 \%)$ não adquiriu problemas de saúde decorrentes do trabalho atual, no entanto mais da metade sentia dores, principalmente na coluna. Entre os operadores que ficaram afastados por problemas de saúde, mais da metade $(73,9 \%)$ foi por acidente no serviço. O exame médico periódico mais realizado pelos trabalhadores era a audiometria.

- Para a maioria dos operadores $(60,9 \%)$, alguns EPIs eram considerados desconfortáveis. A reposição desses equipamentos foi considerada deficiente e insatisfatória por 78,3\%. Grande parte dos operadores já presenciou e sofreu acidente no trabalho $(65,2 \%)$, ao contrário dos auxiliares $(48,7 \%)$. A atividade mais perigosa executada pelos operadores era a poda com motosserra em cima das árvores e para os auxiliares, o trabalho próximo às rodovias. Segundo os trabalhadores, a falta de atenção era o motivo maior de acidentes no trabalho.

- O índice de treinamento dos operadores $(8 \%)$ e auxiliares $(11,3 \%)$ foi considerado muito baixo. Amaioria $(64,3 \%)$ sentia necessidade de fazer cursos de aperfeiçoamento para melhorar o desempenho no serviço e aumentar a segurança.

- A grande maioria dos trabalhadores estava satisfeita $(56,5 \%)$ ou muito satisfeita com a atividade $(34,8 \%)$.

- Todas as motosserras estavam em bom estado de conservação, possuíam sistema de segurança adequado e recebiam manutenções periódicas, sendo avaliadas como muito boas. As motopodas foram avaliadas como boas. As motosserras analisadas estavam em bom estado de conservação e com sistema de segurança adequado. Apenas a quantidade por equipe foi considerada insuficiente. Quanto aos equipamentos e ferramentas de poda, as cordas foram consideradas boas, as escadas ruins e o carrinho adaptado para carregar troncos, regular. Os EPIs estavam bem conservados, considerados bons. Os veículos de transporte dos trabalhadores apresentavam deficiências de projeto, com má distribuição e insuficiência de janelas de ventilação, assentos com pouca inclinação para a coluna, cintos de segurança de duas pontas mal fixados e o primeiro degrau de acesso era muito alto.

\section{AGRADECIMENTOS}

Ao Conselho Nacional de Desenvolvimento Tecnológico $(\mathrm{CNPq})$, pelo apoio.

\section{REFERÊNCIAS BIBLIOGRÁFICAS}

ALVES FILHO, J. P Segurança e saúde na agricultura: Aspectos gerais. In: SEMINÁRIO DA REGIÃO SUL E SUDESTE, Campanha Nacional de Prevenção de Acidentes do Trabalho na Área Rural - CANPATR, 2001, Chapecó. Anais... Chapecó: Representantes de Órgãos Governamentais e Universidades, 2001. p. 8-16.

FIEDLER, N. C. Análise de posturas e esforços despendidos em operações de colheita florestal no litoral norte do estado da Bahia. 1998. 103f. Tese (Doutorado em Ciência Florestal) - Universidade federal de Viçosa, Viçosa, 1996.

MinetTe, L. J. Análise de fatores operacionais e ergonômicos na operação de corte florestal com motosserra. 1996. 211f. Tese (Doutorado em Ciência Florestal) - Universidade Federal de Viçosa, Viçosa, 1996.

PEDROSA, J. B. Arborização de cidades e rodovias. IEF/MG. Belo Horizonte: 1983. 64p.

SALIBA, T., F. CORRÊA, M. A. C.

Insalubridade e periculosidade: aspectos técnicos e práticos. 3. ed. São Paulo: LTr, 1997. 228p.

SANT'ANNA, C. M. Fatores humanos relacionados com a produtividade do operador de motosserra no corte florestal. 1992. 145f. Dissertação (Mestrado em Ciências Florestais). Universidade Federal de Viçosa, Viçosa, 1992

SANT'ANNA, C. M.; MALINOVSKI, J. R Análise de fatores humanos e condições de trabalho de operadores de motosserra de Minas Gerais.

Revista Cerne, v. 8, n. 1, p.115-121. 2002.

SERVIÇO SOCIAL DA INDÚSTRIA - SESI. Departamento Nacional. Série SESI em saúde e segurança no trabalho para indústria. Brasília: SESI/DN, 2002. v2. 106p.

SILVA, M. A. Poda em árvores. In: ALENCAR, F.O.C.C. (Coord.). MANUAL DE JARDINAGEM E PRODUÇÃO DE MUDAS DO DEPARTAMENTO DE PARQUES E JARDINS DPJ. Brasília: NOVACAP/DU/DPJ, 2003. p 69-72.

SOUZA, A. P. MINETTI, L. J. Ergonomia aplicada ao trabalho. In: MACHADO, C.C. (Ed.). Colheita Florestal. Viçosa, MG: Universidade Federal de Viçosa, 2002. p. 293-309.

R. Árvore, Viçosa-MG, v.30, n.2, p.223-233, 2006 